\title{
Down-Regulation of NFkB, Bax,TGF- $\beta$, Smad-2mRNA expression in the Livers of Carbon Tetrachloride Treated Rats using Different Natural Antioxidants
}

\author{
Nouf Mohamed Al-Rasheed ${ }^{1}$; Laila Mohamed Fadda ${ }^{1}$; Nawal Mohamed Al-Rasheed ${ }^{1}$; \\ Hanaa Mahmoud Ali ${ }^{2,3^{*}}$; Hazar Ibrahim Yacoub ${ }^{1}$ \\ 1Pharmacology Department; Faculty of Pharmacy; King Saud University; Riyadh - KSA.; 2Depatment of Genetics \\ and Cytology; National Research Center; Egypt. 3 Preparatory Year Deanship; King Saud University; Riyadh - KSA
}

\begin{abstract}
The objective of this study is to examine whether silymarin alone or in combination with chlorogenic acid and/ or melatonin plays a modulatory role against apoptotic damage in rats liver induced by of $\mathrm{CCl}_{4}$. The present work revealed that $\mathrm{CCl}_{4}$ induced elevation of in Bax, Smad, TGF- $\beta$ and NFkBhepatic mRNA expression, administration of silymarin alone down regulates these expressions. Treatment with chlorogenic acid and/ or melatonin along with silymarin produced best results in this concern. Bcl-2 expression was down regulated by $\mathrm{CCl}_{4}$ whereas concurrent treatment of chlorogenic acid and/ or melatonin along with silymarin increased this expression. On conclusion, the use of chlorogenic acid and/ or melatonin potentiates the anti-apoptotic action of silymarin.
\end{abstract}

Key words: $\mathrm{CCl}_{4}$, Silymarin, Chlorogenic acid, Melatonin, mRNA expression.

*Author for correspondence: hsameh2312003@yahoo.com 


\section{INTRODUCTION}

Liver is the major organ that plays a vital role in human physiology like metabolism of macromolecules and synthesis of useful components (Moreria et al. 2014). Drugs and chemicals cause liver damage which cause extremely severe abnormalities (Andritoiu et al. 2014).The prevalence of chronic liver disease is increasing worldwide with an extensive range of etiologies(Tsochatzis et al. 2014). Cirrhosis is the end stage of both liver fibrosis and liver disease, continues one of the leading causes of death because of the increased risk for developing varietal bleeding, hepatic failure, and hepatocellular carcinoma (HCC) (D'Amico et al. 2006; Rincón et al. 2013).

Generation of free radicals and oxidative stress plays a major role in liver toxicity induced by chemicals (Muhtaseb et al. 2008, Appiah et al. 2009). Carbon tetrachloride is one of the xenobiotic hazardous hepatotoxin (Xiao et al. 2012), which causes liver damage through lipid peroxidation and oxidative stress (Moreria et al. 2014). Its mechanism of toxicity requires a CYP 450-mediated bioactivation step that produces free radicals, such as trichloromethyl $\left(\mathrm{CCl}_{3}\right.$.) (Boelsterli et al. 2007), and induces the peroxidation of lipids. These lipids then damage the membranes of organelles and liver cells, causing the swelling and necrosis of hepatocytes and resulting in the release of cytosolic enzymes such as into the circulating blood (Singh et al. 1998; Shankar et al. 2008). Huda et al. (2014)reported that the administration of $\mathrm{CCl}_{4}$ markedly increased the activity of liver serum biomarker enzymes such as aspartate aminotransferase (AST), Serum ALT, alkaline phosphatase(ALP) and gamma glutamyl transpeptidase $(\gamma-G T)$, triglycerides, total cholesterol, low-density lipoprotein(LDL )cholesterol while decreased the high density lipoprotein(HDL) cholesterol. It decreased the activity of Catalase (CAT), Superoxide dismutase (SOD), Glutathione-S-transferase (GST), Glutathione peroxidase (GSH-Px), Glutathione reductase (GSR), Reduced glutathione (GSH) while increased estimation of lipid peroxidation.Exposure of $\mathrm{CCl}_{4}$ elicited the hepatic DNA damages. It was documented that natural drugs with antioxidant potential can protect the liver from damage caused by $\mathrm{CCl}_{4}$ (Sanmugapriya and Venkataraman 2006; Appiah et al. 2009; Andritoiu et al.2014). $\mathrm{CCl}_{4}$ was shown to increase the level of ALT, while it decreased the B-cell lymphoma 2 (Bcl2) level in rats (Xiao et al. 2013; Mohamed et al. 2015). In addition, Xiao et al. (2013) also reported that the expression of the proapoptotic protein, apoptosis regulator (Bax), was increased in mitochondrial fraction of $\mathrm{CCl}_{4^{-}}$ induced hepatic injury in rats, and the $\mathrm{Bax} / \mathrm{Bcl}-2$ ratio was elevated.

Maintaining the balance between free radicals and antioxidants is therefore important as well as inhibiting inflammatory mediators may serve as major mechanisms in preventing damage impact induced by toxic agents. The implication of oxidative stress and inflammation in the etiology and progression of several acute and chronic clinical disorders has led to the suggestion that agents with antioxidant and anti-inflammatory properties may have health benefits. Several antioxidant agents, including silymarin, antioxidant vitamins ( $\mathrm{C}$ and $\mathrm{E}$ ), and melatonin have been reported to reduce $\mathrm{CCl}_{4}$-induced toxicity (Turkdogan et al. 2001; Shaker et al. 2011).

Silymarin, commercially available as Milk Thistle, is an extract from the seeds of Silybium marianum. The protective effect of silymarin was attributed to its antioxidant and free radical scavenging properties (Ramadan et al. 2002). Several studies revealed that the administration silymarin with $\mathrm{CCl}_{4}$ ameliorated the levels of Bax, Bcl2 and ALT which were disturbed after treatment rats with $\mathrm{CCl}_{4}$ (Yun-Chen et al. 2011; Abdullah et al. 2014). It can prevent lipid peroxidation, inhibit LDL oxidation and scavenge reactive oxygen species (ROS) (Post-White et al. 2007). Moreover, it has anti-inflammatory effects which may relate its ability to inhibit the transcription factor NFkB, which contributes to the production of proinflammatory mediators such as interleukin (IL)- 1 and IL - 6 , TNF- $\alpha$, lymphotoxin, granulocyte macrophage, colony-stimulating factor (GM-CSF) and interferon (IFN $\gamma$ )-c (Deep and Agarwal 2007). Chlorogenic acid (CGA) is the major active ingredient found in many traditional Chinese medicines such as Folium mori (Hunyadi et al. 2012) and Flos Lonicerae japonicae(Oku et al. 2011), and it is also abundant in some fruits, dietary vegetables (Gavrilova et al. 2011), and daily beverages like coffee (del Rio et al. 2010). CGA has been reported to possess anti-bacterial, antioxidant, and anti-carcinogenic properties (Kono et al. 1997; dos Santos et al. 2006). CGA has also been reported to be a potent polyphenolic antioxidant because it contains a certain amount of 
the R-OH group, which can bind with hydroxyl radicals and superoxide anion radicals to protect cells from oxidative injury (Özyürek et al. 2008). Ji et al. (2013) found that CGA can prevent acetaminophen induced liver injury through regulating liver glutathione (GSH) and thioredoxin (Trx) antioxidant systems.

Melatonin (N-acetyl-5-methoxytryptamine) (Mel) is a hormone secreted by pineal gland and is mainly responsible for controlling circadian cycle (Sehajpal et al. 2014). This small amphiphilic molecule and its metabolites are likewise potent scavengers of ROS (Wang et al. 2011). Apart from this, Mel was shown to possess an antiinflammatory and antiapoptotic actions (Mauriz et al. 2013). Mel improved the recovery of renal function by decreasing endoplasmic reticulum(ER) stress and stimulating Akt pathway after renal ischemia/reperfusion $\mathrm{I} / \mathrm{R}$ injury (Kaouther et al. 2015). In a rat model of thioacetamide (TAA)induced fulminant hepatic failure, it was suggested that melatonin may be utilized to reduce liver injury associated with oxidative stress by inhibiting NFkBactivation (Bruck et al. 2004). It was reported that liver apoptotic cell death is induced by ROS species, via the intrinsic signaling pathway, and that the anti-apoptotic action provided by melatonin is related to its antioxidant effect, with reduction of cytochrome $\mathrm{c}$ release by the modulation of Bcl-2 and Bax genes (Virginia et al. 2007).

The current study was designed to find out the hepatoprotective role of silymarin through its antiapoptotic effect. Moreover to detect if chlorogenic acid and/or melatonin co-activate the antiapoptotic effect of silymarin against $\mathrm{CCl}_{4}$ induced oxidative liver injury in rats.

\section{MATERIAL AND METHODS}

\section{Chemicals}

All reagents used were of high analytical grade, product of Sigma and Merck companies. Silymarin, chlorogenic acid and melatonin were obtained from Sigma Chemical Co. (Sigma, St. Louis, MO, USA).

\section{Animals and treatments}

Sixty healthy male albino rats $(120-150 \mathrm{~g})$ of Sprague-Dawley strain were obtained from the Experimental Animal Center, Faculty of Pharmacy, King Saud University, Saudi Arabia, Riyadh. The animal experimental protocol was approved by the Animal Care and Ethical Committee of Faculty of Pharmacy, King Saud University. Animals were housed in clean acrylic cages and maintained under standard conditions (12-h light/12-h dark cycle) with a controlled temperature of 20 to $22^{\circ} \mathrm{C}$ and humidity of $60 \%$. Rats were fed a standard rat pellet diet with free access to tap water ad libitum for oneweek for acclimatization. After one week of acclimation, the rats were fasted overnight before treatment and were divided randomly into six groups, each of ten rats as follows:

Group 1: Normal healthy control rats, Group 2: $\mathrm{CCl}_{4}$-intoxicated rats, Group 3: $\mathrm{CCl}_{4}$-intoxicated rats treated with silymarin alone, Group $4: \mathrm{CCl}_{4^{-}}$ intoxicated rats treated with silymarin and chlorogenic acid, Group 5: $\mathrm{CCl}_{4}$-intoxicated rats treated with silymarin and melatonin and Group 6: $\mathrm{CCl}_{4}$ intoxicated rats treated with a combination of silymarin, chlorogenic acid and melatonin.

A single dose of $\mathrm{CCl}_{4}$ was injected intraperitoneally to the rats as a mixture of corn oil and $\mathrm{CCl}_{4}(1: 1,1 \mathrm{~mL} / \mathrm{kg}$ body weight, $0.5 \mathrm{~mL}$ $\mathrm{CCl}_{4}+0.5 \mathrm{~mL}$ corn oil) (Yachi et al. 2010). Silymarin $(200 \mathrm{mg} / \mathrm{Kg} / \mathrm{day})$ (Li et al. 2012) cholorogenic acid $(60 \mathrm{mg} / \mathrm{Kg} /$ day) ( Shi et Al. 2009) and melatonin ( $20 \mathrm{mg} / \mathrm{Kg} /$ day) (Laliena et al. 2012) were suspended in gum acacia $(2 \% \mathrm{w} / \mathrm{v})$ and given orally once daily for 21 successive days, $24 \mathrm{~h}$ post $\mathrm{CCl}_{4}$ injection. After the experimental period, blood samples were collected from each animal in all groups into sterilized tubes for serum separation. Serum was separated by centrifugation at $1006 \mathrm{~g}$ for $10 \mathrm{~min}$ and used for biochemical serum analysis. After blood collection, the rats of each group were sacrificed under ether anesthesia, and their livers were collected, weighed and washed using chilled saline solution. The livers were minced and homogenized in ice-cold bidistilled water to yield $10 \%$ homogenates. The homogenates were centrifuged for $15 \mathrm{~min}$ at 1789 $\mathrm{g}$ at $4^{\circ} \mathrm{C}$, and the supernatants were used for biochemical tissue analysis.

\section{Determination of serum alanine aminotransferase (alt)}

Diagnostic kits were purchased from Randox Company Chemical CO, ALT was determined according to the method of Reitman and Frankel (1957), following the instructions of the manufacturer Quantitative Real-Time Polymerase Chain Reaction (Qrt-Pcr) for Analysis of Hepatic Nf-Kb, Bax, Bcl2, Tgf-B, Smad-2 Mrna Expression Principle Detection of Gene Expression Using Real Time PCR (RT-PCR) 


\section{Total RNA Extraction}

Total RNA was isolated from hepatic tissue homogenates using RNeasy Purification Reagent (Qiagen, Valencia, CA) according to manufacturer's instruction. The purity (A260/A280 ratio) and the concentration of RNA were obtained using spectrophotometry (GeneQuant 1300, Uppsala, Sweden). RNA quality was confirmed by gel electrophoresis on a $1 \%$ agarose gel stained with ethidium bromide.

\section{cDNA Synthesis and qRT-PCR}

First-strand cDNA was synthesized from $4 \mu \mathrm{g}$ of total RNA using an Oligo(dT)12-18 primer and Superscript ${ }^{\mathrm{TM}}$ II RNase Reverse Transcriptase. This mixture was incubated at $42^{\circ} \mathrm{C}$ for $1 \mathrm{~h}$; the kit was supplied by Superscript Choice System (Life Technologies, Breda, the Netherlands).

Equal amounts of RNA $(2 \mu \mathrm{g})$ were reverse transcribed into cDNA using Superscript Choice systems (Life Technolgies, Breda, Netherlands) according to the manufacturer's instructions. To assess the mRNA expression of Bax, Bcl2, NFkB, Smad-2 and TGF- $\beta$ quantitative real-time PCR was performed using SYBR green PCR Master mix (Applied Biosystems, CA, USA) as described by the manufacturer. Briefly, in a $25 \mu \mathrm{L}$ reaction volume, $5 \mu \mathrm{L}$ of cDNA was added to $12.5 \mu \mathrm{L}$ of $2 \times$ SYBR green Master mix,200 ng of each primer and $5 \mu \mathrm{L}$ RNase free water(Into a single $50 \mu \mathrm{L}$ reaction, add $10 \mu \mathrm{L}$ of $20 \mu \mathrm{g}$ primer/mL template stock to give $200 \mathrm{ng}$ of primer in that tube). The sequences of primers are described in Table 1 . The PCR reactions included $10 \mathrm{~min}$ at $95^{\circ} \mathrm{C}$ (activation), followed by 40 cycles at $94^{\circ} \mathrm{C}$ for 15 $\mathrm{sec}$ (denaturing) and $60^{\circ} \mathrm{C}$ for $1 \mathrm{~min}$ (annealing/extension). The expression level was calculated from the PCR cycle number (CT) where the increased fluorescence curve passes across a threshold value. The relative expression of target genes was obtained using comparative $\mathrm{CT}(\Delta \Delta \mathrm{CT})$ method. The $\Delta \mathrm{CT}$ was calculated by subtracting $\beta$ actin CT from that of target gene whereas $\Delta \Delta \mathrm{CT}$ was obtained by subtracting the $\Delta \mathrm{CT}$ of calibrator sample (control group) from that of test sample (2, $3,4,5,6$ groups). The relative expression was calculated from $2^{-\Delta \Delta C T}$ formula (Livak and Schmittgen 2001).

Table 1- Primersequencesas prescribed in other literaturesused for RT-PCR

\begin{tabular}{|c|c|c|}
\hline Gene name & Primer sequence & Primer size (bp) \\
\hline Refer-actin & $\begin{array}{l}\text { Forward 5' GAGACCTTCAACACCCCAGC 3' } \\
\text { Reverse 5' ATGTCACGCACGATTTCCC 3' }\end{array}$ & 263 \\
\hline NFkB & $\begin{array}{l}\text { Forward 5' CATGAAGAGAAGACACTGACCATGGAAA3' } \\
\text { Reverse 5' TGGATAGAGGCTAAGTGT AGACACG 3' }\end{array}$ & 329 \\
\hline Bax & $\begin{array}{l}\text { Forward 5' GTTGCCCTCTTCTACTTTG 3' } \\
\text { Reverse 5' AGCCACCCTGGTCTTG 3' }\end{array}$ & 194 \\
\hline Bcl-2 & $\begin{array}{l}\text { Forward 5'CGGGAGAACAGGGTATGA 3' } \\
\text { Reverse 5' CAGGCTGGAAGGAGAAGAT 3' }\end{array}$ & 224 \\
\hline TGF- $\beta 1$ & $\begin{array}{l}\text { Forward 5' TGCTAATGGTGGACCGCAA 3' } \\
\text { Reverse 5' CACTGCTTCCCGAATGTCTGA 3' }\end{array}$ & 329 \\
\hline Smad-2 & $\begin{array}{l}\text { Forward 5' TCTCCGGCTGAACTGTCTCCTA 3' } \\
\text { Reverse 5' GCGATTGAACACCAGAATGCA 3' }\end{array}$ & 267 \\
\hline
\end{tabular}

F: Forward primer sequence R: Reverse primer sequence

\section{Determination of Protein Level:}

The protein content of the different fractions resulted from centrifugation of liver homogenate was determined according to the method of Wray et al. (1981).

\section{Statistical analysis}

Data were expressed as means \pm SEM. The results were analyzed statistically by One-way analysis of variance (ANOVA) using SPSS (Statistical Package for the Social Sciences, version
16.0.1, Chicago, IL) software. Individual treatment means were compared post hoc by the Scheffé test. The level of significance was set at $\mathrm{p}<0.05, \mathrm{p}<$ 0.01 and $\mathrm{p}<0.001$. Statistical analysis was performed using Graph pad Instat 3 software Inc, San Diego, CA, USA.

Limit of significance for figures 1 to $6: \mathrm{P}<0.001$ 


\section{RESULTS}

Table 2 represents the serum ALT activities, expression in control, $\mathrm{CCl}_{4}$ intoxicated and different treated groups.

NFkB, Bax, Bcl2, TGF- $\beta$, Smad-2 and mRNA

Table 2- Serum ALT activity and hepatic NFkB, Bax, Bcl2, TGF- $\beta$, Smad-2 mRNAexpression in control, $\mathrm{CCl}_{4}$ intoxicated and different treated groups.

\begin{tabular}{|c|c|c|c|c|c|c|}
\hline & \multirow{2}{*}{$\begin{array}{l}\text { Serum } \\
\text { ALT } \\
\text { (ULL) }\end{array}$} & \multicolumn{2}{|c|}{ Hepatic mRNA expression } & \multirow[b]{2}{*}{$\mathrm{Bcl} 2$} & \multirow[b]{2}{*}{ TGF- $\beta$} & \multirow[b]{2}{*}{ Smad-2 } \\
\hline & & NFkB & Bax & & & \\
\hline Control & $\begin{array}{ll}48.29 & \pm \\
3.12 & \end{array}$ & $1.07 \pm 0.1$ & $1.11 \pm 0.08$ & $1.26 \pm 0.15$ & $1.09 \pm 0.09$ & $1.4 \pm 0.51$ \\
\hline $\mathrm{CCl}_{4}$ & $107 \pm 16.29$ & $12.2 \pm 1.17$ & $14.56 \pm 0.68$ & $0.23 \pm 0.2$ & $11.6 \pm 0.91$ & $11.93 \pm 1.45$ \\
\hline Sil & $74.5 \pm 7.80$ & $7.73 \pm 0.37$ & $9.4 \pm 0.55$ & $\begin{array}{l}0.34 \pm \\
.0 .03^{* * * *_{a}}\end{array}$ & ${ }_{* * * a \mathrm{ab}}^{9.03 \pm 0.2}$ & $7.8 \pm 0.5$ \\
\hline Sil + CGA & $68 \pm 9.41$ & $\underset{* * * a \mathrm{ab}}{5.54 \pm 0.46}$ & $\underset{* * * 36 \pm 1.06}{* a b}$ & $\underset{* * * a b}{0.7 \pm} 0.13$ & $\begin{array}{l}7.14 \pm 1.1 \\
* * * a b\end{array}$ & $5.97 \pm 0.15$ \\
\hline Sil + Mel & $65 \pm 5.81$ & $\begin{array}{l}3.8 \pm 0.4 \\
* * * a b\end{array}$ & $5.2 \pm 0.26$ & $0.67 \pm 0.02$ & $\underset{* * * a b}{5.23} \pm 0.24$ & $\underset{* * * a b}{4.16} \pm 0.35$ \\
\hline $\begin{array}{l}\text { Sil+ CGA+ } \\
\text { Mel }\end{array}$ & $55.4 \pm 5.09$ & $1.9 \pm 0.34$ & $2 \pm 0.2$ & $\begin{array}{l}0.95 \pm \\
0.07 \\
* * * *^{*} / * \mathrm{a}_{\mathrm{a}}\end{array}$ & $3.26 \pm 0.21$ & $2.37 \pm 0.57$ \\
\hline
\end{tabular}

The current results of this study revealed that the ALT activity was significantly elevated in the $\mathrm{CCl}_{4}$ treated group $(\mathrm{p}<0.001)$, while the supplement of sil either alone or in combination with CGA and/ or Mel significantly downregulated the elevation of the serum ALT versus $\mathrm{CCl}_{4}$ intoxicated rats as compared with $\mathrm{CCl}_{4}$ treated group (Fig. 1). Coadministration of the three antioxidants was the most effective treatment; hence, it caused the greatest reduction in the activity of the serum liver enzyme in $\mathrm{CCl}_{4}$ intoxicated rats.

NFkB, proapoptic protein (Bax), TGF- $\beta$ and Smad-2 expression levels in $\mathrm{CCl}_{4}$ treated groupswere significantly higher than those in the control group $(p<0.001)$. Post-treatment of the rats with sil either alone or in combination with CGA and/ or Mel produce high significant reduction of these levels compared with both control and $\mathrm{CCl}_{4}$ treated rats, such reduction in the expression of TGF- $\beta$ was highly significant compared with both control and $\mathrm{CCl}_{4}$ treated groups (Figs. 2, 3, 5, 6). While the anti-apoptic protein $\mathrm{Bcl} 2$ expression levels were highly significant reduced in the $\mathrm{CCl}_{4}$ intoxicated rats compared with the control group $(\mathrm{p}<0.001)$. Treatment of the $\mathrm{CCl}_{4}$ group with the aforementioned antioxidants ameliorated these levels compared with both control and $\mathrm{CCl}_{4}$ treated groups (Fig. 4).

The administration of the combination of Sil, CGA and Mel revealed the most protective effect against $\mathrm{CCl}_{4}$ hepatotoxicity (Figs. 2, 3, 4, 5, 6).

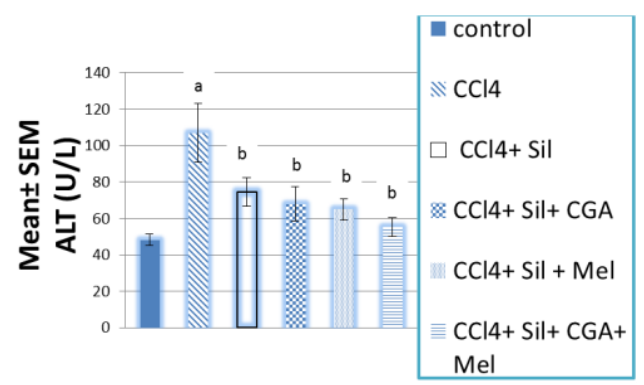

a: Significantly different from control group. b: Significantly different from $\mathrm{CCl}_{4}$-treated group. Figure 1- ALT activities in the serum of control and different treated groups. 
Ali, HM et al.

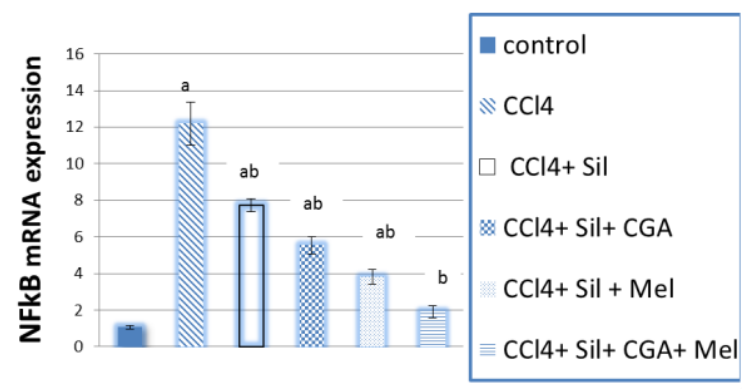

a: Significantly different from control group.

b: Significantly different from $\mathrm{CCl}_{4}$-treated group.

Figure 2- NFkB mRNA expression in the liver of control and different treated groups.

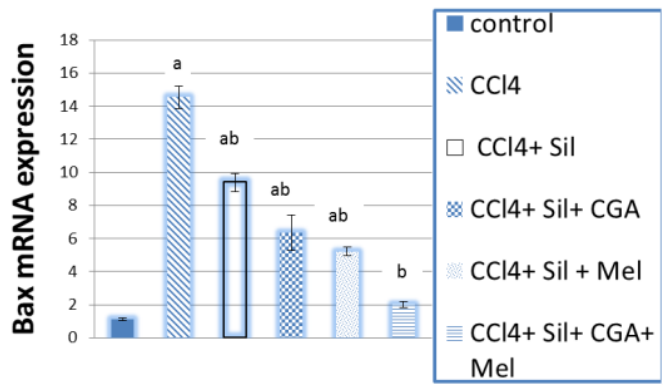

a: Significantly different from control group.

b: Significantly different from $\mathrm{CCl}_{4}$-treated group.

Figure 3- BaxmRNA expression in the liver of control and different treated groups.

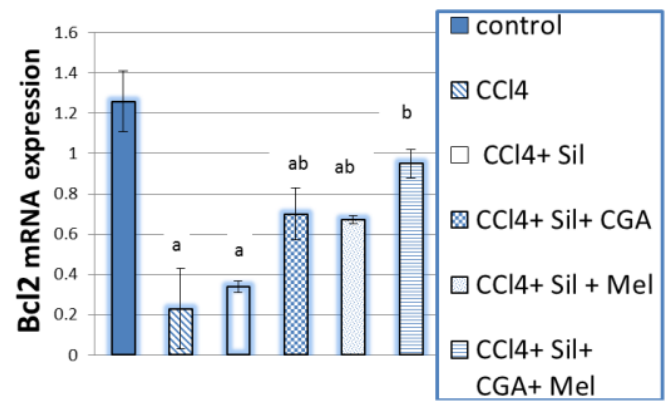

\section{DISCUSSION}

Liver fibrosis is the common scarring response of the liver to most chronic liver damage. Continuous chronic liver damage leads to a progressive accumulation of scarring proteins and finally, alters normal tissue structure and function by inducing fibrosis, cirrhosis and ultimately liver failure. Liver fibrosis and cirrhosis is mediated by various cytokines including TNF- $\alpha$, IL-10 and TGF- $\beta$, it has been shown that TGF- $\beta$ plays the most significant role in chronic liver disease. In the middle stage of fibrosis or cirrhosis, TGF- $\beta$ is produced predominantly in hypoxic hepatocytes. Therefore, understanding the role of TGF- $\beta$, and inhibiting TGF- $\beta$ release in chronic liver disease, might be the key to developing an effective a: Significantly different from control group. b: Significantly different from $\mathrm{CCl}_{4}$-treated group. Figure 4- Bcl2mRNA expression in the liver of control and different treated groups

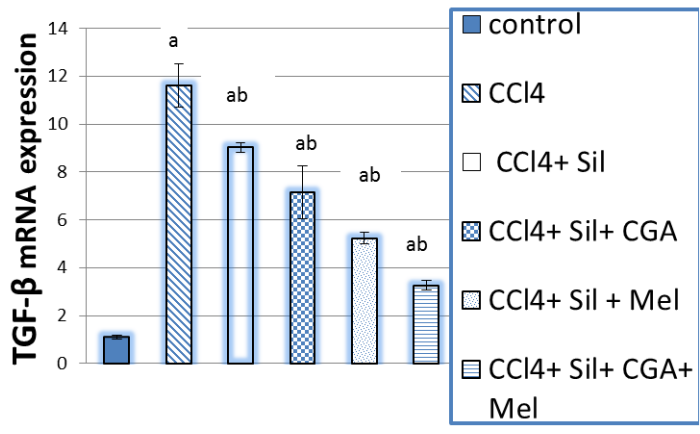

a: Significantly different from control group. b: Significantly different from $\mathrm{CCl}_{4}$-treated group.

Figure 5- TGF- $\beta m R N A e x p r e s s i o n$ in the liver of control and different treated groups.

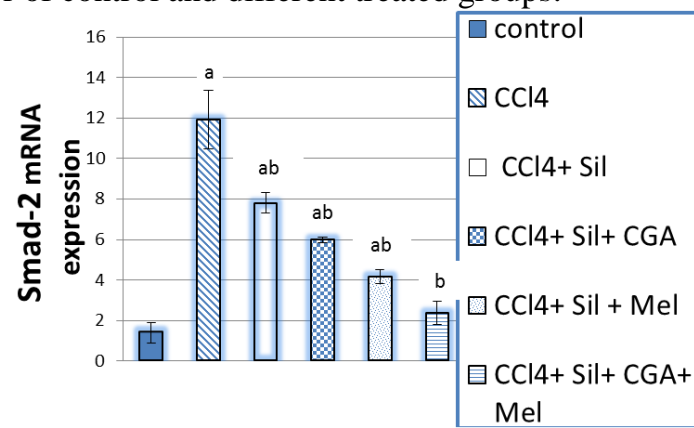

a: Significantly different from control group. b: Significantly different from $\mathrm{CCl}_{4}$-treated group Figure6 - Smad-2mRNA expression in the liver of control and different treated groups.

therapeutic strategy for liver fibrosis, cirrhosis and chronic liver disease (Kyu-Shik 2008). TGF- $\beta$ and its related factors were reported to induce apoptosis in a variety of tissues. TGF- $\beta$ induces the expression of the death-associated protein kinase (DAP-kinase) a positive mediator of apoptosis induced by certain cytokines and oncogenes. This effect is regarded as an immediate early response in cells that undergo apoptosis in response to TGF- $\beta$. DAP-kinase promoter is activated by TGF- $\beta$ through the action of Smad2, Smad 3 and Smad4. DAP-kinase mediates TGF- $\beta$ dependent apoptosis by linking Smads to mitochondrial-based pro-apoptotic events (Bakhshayesh et al. 2012). The Smad family comprises transcription factors that function as signal transducers of TGF- $\beta$ superfamily members. Activation of Smads by TGF- $\beta$ family members 
results in fibrotic, apoptotic, and anti-hypertrophic processes (Bakhshayesh et al. 2012).

Liver injury can be induced by the hepatotoxin $\left(\mathrm{CCl}_{4}\right)$ which is mainly metabolized by cytochrome P450 2E1 (CYP2E1). Unstable free radicals and ROS generated by this metabolic pathway induce liver cell apoptosis and necrosis. The ROS and free radicals induce the upregulation of TNF- $\alpha$, IL-10 and TGF- $\beta$ in necrotic hepatocytes. Increased cytokines, especially TGF$\beta$, activate local resident leucocytes and promote the recruitment of circulating leucocytes to the necrotic area; consequently TGF- $\beta$ accelerates the progression of liver injury from the acute stage to chronic liver disease (Kyu-Shik 2008). Moreover, it has been reported that $\mathrm{CCl}_{4}$ increase $\mathrm{NFkB}$, which regulates the transcription of several genes including cytokines such as the profibrogenic TGF- $\beta$ in rat (Chávez et al. 2008).

$\mathrm{CCl}_{4}$ was shown to increase the level of ALT, while it decreased Bcl2 level in rats (Mohamed et al. 2015;Xiao et al. 2013). Xiao et al. (2013) also reported that the expression of the pro-apoptotic protein, (Bax), was increased in mitochondrial fraction of $\mathrm{CCl}_{4}$-induced hepatic injury in rats, and the $\mathrm{Bax} / \mathrm{Bcl}-2$ ratio was elevated.

It was documented that cellular adenosine triphosphate (ATP) depletion initiates the translocation of Bax, a proapoptotic Bcl-2 family member protein, from the cytosol to the outer mitochondrial membrane. The translocation of Bax causes mitochondrial dysfunction and swelling, and can induce the efflux of cytochrome $c$ to the cytosol (Malhi et al. 2006). Bcl-2 functions to prevent cell death, whereas Bax appears to accelerate the cell death signal (Green and Reed 1998). Our results confirm a significant decrease $(\mathrm{P}<0.001)$ in $\mathrm{Bcl}-2$ content accompanied by the increase of $\mathrm{Bax}$ by $\mathrm{CCl}_{4}$ treatment as compared with control group.

The implication of oxidative stress and inflammation in the etiology and progression of several acute and chronic clinical disorders has led to the suggestion that agents with antioxidant and anti-inflammatory properties may have health benefits. Several antioxidant agents, including silymarin, antioxidant vitamins (C and $\mathrm{E})$, and melatonin have been reported to reduce $\mathrm{CCl} 4-$ induced toxicity (Turkdogan et al. 2001; Shaker et al. 2011).

Silymarin is a flavonoid extracted from the milk thistle Silybum marianum. Although silymarin has been described to possess antioxidant, immunomodulatory, antiproliferative, antifibrotic, and antiviral activities (Saller et al. 2001), its mechanisms of action still have not been well established (Wei et al. 2013).

It has been reported that silymarin protects against liver injury caused by ethanol administration. The effect may be related to alleviating lipid peroxidation and inhibiting the expression of NFkB(Wei et al. 2013). Several studies revealed that the co-administration of silymarin with $\mathrm{CCl} 4$ ameliorated the levels of Bax, Bcl2 and ALT which were disturbed after treatment rats with CCl4 (Yun-Chen et al. 2011; Abdullah et al. 2014). It can prevent lipid peroxidation, inhibit lowdensity lipoprotein oxidation and scavenge reactive oxygen species ROS (Post-White et al. 2007). Moreover, it has anti-inflammatory effects which may relate its ability to inhibit NFkB, which contributes to the production of proinflammatory mediators such as IL-1 and IL -6, TNF- $\alpha$, lymphotoxin, granulocyte macrophage, colonystimulating factor (GM-CSF) and interferon (IFN)c (Deep and Agarwal 2007). The results of the present work revealed that $\mathrm{CCl}_{4}$ induced highly significant elevation $(p<0.001)$ of ALT with concomitant increase in Bax, Smad2, TGF- $\beta$ and NFkB hepatic mRNA expression, administration of silymarin alone down regulates these expressions.

Furthermore, melatonin treatment increased the levels of antiapoptotic Bcl-2 and reduced the proapoptotic protein Bax support its antiapoptotic role. Thus, the ability of melatonin to enhance the level of Bcl-2 has been demonstrated in rat brain (Baydas et al. 2005), and it has been shown that melatonin treatment is able to prevent $\mathrm{H}_{2} \mathrm{O}_{2}$ induced apoptosis by regulating Bax expression in a model of cultured rat astrocytes (Juknat et al. 2005). Recent research indicates that early melatonin supplementation significantly reduces upregulated expression of Bax and caspase- 3 in a transgenic mouse model of Alzheimer's disease (Feng et al. 2006). Protective effects of melatonin appear to be related to its antioxidant capacity, which limits loss of intramitochondrial glutathione and lowers mitochondrial protein damage (Martin et al. 2000), and to the improvement in the electron transport chain activity (Martin et al. 2002). A major consequence is the prevention of the harmful reduction in the mitochondrial membrane potential that may trigger MPT pores opening and the apoptotic cascade (Xu and Ashraf 2002).

In the model of aging, caspase- 3 activation and apoptotic cell death is induced by ROS, via the intrinsic signaling pathway, and that the antiapoptotic action provided by melatonin is 
related to its antioxidant effect, with reduction of cytochrome $c$ release by the modulation of $\mathrm{Bcl}-2$ and Bax genes (Molpeceres et al. 2007).

Chávez et al. (2008) reported that melatonin possesses a strong antifibrogenic effect in the $\mathrm{CCl}_{4}$ model of cirrhosis. Moreover, the action mechanism is probably associated with its ability to reduce NFkBactivation and TGF- $\beta$ content (Chávez et al. 2008). Co-administration of melatonin with silymarin significantly reduced serum ALT activity at $\mathrm{p}<0.01$ compared with control group and at $\mathrm{p}<0.001$ compared with $\mathrm{CCl}_{4}$ treated rats as well as NFkB, bax, TGF- $\beta$ and Smad-2 expression at $\mathrm{P}<0.001$ compared with both control and $\mathrm{CCl}_{4}$ treated groups.

Chlorogenic acid is a type of phenolic acid created by the condensation of caffeic acid and quinic acid, also known as 5-coffee quinic acid. It is widely available in seeds, fruits, vegetables and coffee drinks and is also the main functional ingredient in herbal honeysuckle and eucommia. It down regulates TGF- $\beta 1$ protein expression in the kidney of $d b / d b$ Mice (Jin et al. 2015).

Chlorogenic acid resulted in lower injury $(p<0.05)$ and decreased NFkBexpression $(\mathrm{p}<0.05)$ in dextran sodium sulfate treated rats (Leigh et al. 2011).

It was reported that Beta-amyloid $\mathrm{A} \beta$ decreased significantly the viability of PC12 cells. This was accompanied by an increase in the intracellular calcium levels and cleaved caspase-3. In addition, $\mathrm{A} \beta$ induced an increase in Bax, and a decrease in Bcl-2 compared to the controls. However, a pretreatment with chlorogenic acid rescued the PC12 cells from $\mathrm{A} \beta$ by attenuating the elevated intracellular calcium levels and reducing the levels of the apoptosis related proteins, including caspase-3and Bax (Chan et al. 2011).

\section{CONCLUSION}

In this current study co-administration of chlorogenic acid and melatonine with silymarin produced best results in this concern. On the otherhand, Bcl-2 mRNA expression was down regulated by $\mathrm{CCl}_{4}$ whereas concurrent treatment of chlorogenic acid and/ or melatonin with silymarin increased its expression. Therefore, it possible concludes that the use of chlorogenic acid and/ or melatonin potentiates the anti-apoptotic and antifibrogenic effects of silymarin. In addition, the use of this combination may be beneficial in the treatment of various liver disorders.

\section{ACKNOWLEDGMENT}

This research project was supported by a grant from the 'Research Center for Female Scientific and Medical Colleges', Deanship of Scientific Research, King Saud University.

\section{REFRENCES}

Abdullah A, Muhammed İC. Milk thistle impedes the development of carbontetrachloride-induced liver damage in rats through suppression of bcl-2 and regulating caspase pathway. Life Sciences. 2014;117:13-18

Andritoiu CV, Andritoiu V, Cuciureanu M, Nica-Badea D, Bibire N, Popa M. Effect of apitherapy products against carbon tetrachloride induced toxicity in Wistar rats. Rom J Morphol Embryol. 2014;55:835-847.

Appiah I, Milovanovic S, Radojicic A, Nikolic-Kokic A, Orescanin-Dusic Z, Slavic M, et al. Hydrogen peroxide affects contractile activity and anti-oxidant enzymes in rat uterus. $\mathrm{Br} J$ Pharmacol. 2009;158:1932-1941.

Bakhshayesh M, Zaker F, Hashemi M, Katebi M, Solaimani M. TGF- $\beta 1$-mediated apoptosis associated with SMAD-dependent mitochondrial Bcl-2 expression. Clin Lymphoma Myeloma Leuk. 2012;12(2):138-143.

Baydas G, Reiter RJ, Akbulut M, Tuzcu M, Tamer S. Melatonin inhibits neural apoptosis induced by homocysteine in hippocampus of rats via inhibition of cytochrome c translocation and caspase- 3 activation and by regulating pro- and anti-apoptotic protein levels. Neuroscience.2005;135:879-886.

Boelsterli UA. Mechanistic Toxicology: The molecular basis of how chemicals disrupt biological targets. Boca Raton: CRC Press: Boelsterli UA; Xenobioticinduced oxidative stress: cell injury, signaling and gene regulation. 2007;pp. 117-175.

Bruck R, Aeed H, Avni Y, Shirin H, Matas Z, Shahmurov M, et al. Melatonin inhibits nuclear factor kappa $\mathrm{B}$ activation and oxidative stress and protects against thioacetamide induced liver damage in rats. $J$ Hepatol. 2004; 40(1):86-93.

Chan WL, Tae JW, Hak RK, Dongho L, Kwang WH, So-Young P. Protective Effect of Chlorogenic Acid against Beta-amyloid Induced Neurotoxicity. Biomol Ther. 2011;19(2):181-186 .

Chávez E, Reyes-Gordillo K, Segovia J, Shibayama M, Tsutsumi V, Vergara $\mathrm{P}$, et al. Resveratrol prevents fibrosis, NF-kappaB activation and TGF-beta increases induced by chronic $\mathrm{CCl} 4$ treatment in rats. $J$ Appl Toxicol. 2008;28(1):35-43.

D’Amico G, Garcia-Tsao G, Pagliaro L. Natural history and prognostic indicators of survival in cirrhosis: a systematic review of 118 studies. J Hepatol. 2006; 44: 217-231. 
Deep G, Agarwal R. Chemopreventive efficacy of silymarin in skin and prostate cancer. Integr. Cancer Ther. 2007;6: 130-145.

del Rio D, Stalmach A, Calani L, Crozier A. Bioavailability of coffee chlorogenic acids and green tea flavan-3-ols. Nutrients. 2010;2(8):820-833.

Donder E, Baydas G, Ozkan Y, Ercel E, Yalniz M. Investigation of antioxidant effect of melatonin against carbon tetrachloride toxicity in various tissues. Biomed Res.1999;10:141-145.

dos Santos MD, Almeida MC, Lopes NP, Norberto PL,

Glória EP. Evaluation of the anti-inflammatory, analgesic and antipyretic activities of the natural polyphenol chlorogenic acid. Biol Pharm Bull. 2006;29(11):2236-2240.

Feng Z, Qin C, Chang Y, Zhang JT. Early melatonin supplementation alleviates oxidative stress in a transgenic mouse model of Alzheimer's disease. Free Radic Biol Med. 2006;40:101-109.

Gavrilova V, Kajdzanoska M, Gjamovski V,Stefova M. Separation, characterization and quantification of phenolic compounds in blueberries and red and black currants by HPLC-DAD-ESI-MSn . J Agric Food Chem. 2011; 59(8):4009-4018.

Green DR, Reed JC. Mitochondria and apoptosis. Science. 1998; 281:1309-1312.

Huda MA, Rahmat AKMRK, Sumaira S. $\mathrm{CCl}_{4}$ induced genotoxicity and DNA oxidative damages in rats: hepatoprotective effect of Sonchus arvensis. BMC Complementary and Alternative Medicine. 2014, 14:452

Hunyadi A, Martins A, Hsieh TJ,Seres A, Zupkó I. Chlorogenic acid and rutin play a major role in the in vivo anti-diabetic activity of Morus alba leaf extract on type II diabetic rats. PLoS One. 2012;7(11):e50619.

Ji LL, Jiang P, Lu B, Sheng Y, Wang X, Wang Z. Chlorogenic acid, a dietary polyphenol, protects acetaminophen-induced liver injury and its mechanism. J Nutr Biochem. 2013;24(11): 1911-1919.

Jin S, Chang C, Zhang L, Liu Y, Huang X, Chen Z. Chlorogenic Acid Improves Late Diabetes through Adiponectin Receptor Signaling Pathways in $\mathrm{db} / \mathrm{db}$ Mice. PLoS One. 2015; 10(4): e0120842.

Juknat AA, Mendez M del V, Quaglino A, Fameli CI, Mena M, Kotler ML. Melatonin prevents hydrogen peroxide-induced Bax expression in cultured rat astrocytes. J Pineal Res. 005;38:84-92.

Kaouther HAT, Asma MB, Mohamed AZ, Rym K, Mohamed B, Sonia GM, et al. Melatonin Modulates Endoplasmic Reticulum Stress and Akt/GSK3-Beta Signaling Pathway in a Rat Model of Renal Warm Ischemia Reperfusion. Anal Cell Pathol. (Amst). 2015; 2015: 635172.

Kono Y, Kobayashi K, Tagawa S, Adachi K, Ueda A, Sawa Y, et al. Antioxidant activity of polyphenolics in diets: rate constants of reactions of chlorogenic acid and caffeic acid with reactive species of oxygen and nitrogen. Biochim Biophys Acta. 1997; 1335(3):335-342.
Kyu-Shik J. Therapeutic target for chronic liver fibrosis by regulation of transforming growth factor-beta. Basic and Applied Pathology. 2008; 1: 56-60.

Laliena A, San Miguel B, Crespo I, Alvarez M, Gonza'lezGallego J, Tuño'n MJ. Melatonin attenuates inflammation and promotes regeneration in rabbits with fulminant hepatitis of viral origin. $J$ Pineal Res. 2012;53 (3): 270-278.

Leigh AP, Stehm RE, Krenek KA, Weeks BR, Carroll RJ, Byrne DH, et al. Chlorogenic acid reduced DSSinduced injury and NFKB activation in a rat colitis model. The FASEB J. 2011;25:773.713.

Li CC, Hsiang CY, Wu SL, Ho TY. Identification of novel mechanisms of silymarin on the carbon tetrachloride-induced liver fibrosis in mice by nuclear factor-jB bioluminescent imagingguided transcriptomic analysis. Food Chem Toxicol. 2012;50 (5): 1568-1575.

Livak KJ, Schmittgen TD. Analysis of relative gene expression data using real-time quantitative PCR and the 2 (-Delta Delta C (T)) Method. Methods. 2001; 25: 402-408.

Malhi H, Gores GJ, Lemasters JJ. Apoptosis and necrosis in the liver: a tale of two deaths? Hepatology. 2006;43:S31-S44.

Martin M, Macias M, Escames G, Leon J, AcunaCastroviejo D. Melatonin but not vitamins $\mathrm{C}$ and $\mathrm{E}$ maintains glutathione homeostasis in t-butyl hydroperoxide-induced mitochondrial oxidative stress. The FASEB J. 2000;14:1677-1679.

Martin M, Macias M, Leon J, Escames G, Khaldy H, Acuna-Castroviejo D. Melatonin increases the activity of the oxidative phosphorylation enzymes and the production of ATP in rat brain and liver mitochondria. Int J Biochem Cell Biol. 2002;34:348357.

Mauriz JL, Collado PS, Veneroso C, Reiter RJ, Gonzalez-Gallego J. A review of the molecular aspects of melatonin's anti-inflammatory actions: recent insights and new perspectives. J Sur Res. 2013; 54(1):1-14.

Mohamed MH, Naif OA, Ali RA, Khaled AA, Shakir DA, Salim SA, et al. Hepato-protective effect of rutin via IL-6/STAT3 pathway in CCl4-induced hepatotoxicity in rats. Biological Research. 2015; 48:30.

Molpeceres V, Mauriz JL, García-Mediavilla MV, González P, Barrio JP, González-Gallego J. Melatonin Is Able to Reduce the Apoptotic Liver Changes Induced by Aging Via Inhibition of the Intrinsic Pathway of Apoptosis. J Gerontol A Biol Sci Med Sci. 2007; 62 (7): 687-695

Moreira PR, Maioli MA, Medeiros HCD, Guelfi M, Pereira FTV, Mingatto FE. Protective effect of bixinon carbon tetrachloride induced hepatotoxicity in rats. Biol Res. 2014; 47:49.

Muhtaseb MS, El Talwar D, Duncan AJ, O'reilly D, Mckee RF, Anderson JH, et al. Free radical activity and lipid soluble anti-oxidant vitamin status in patients with longterm ileal pouch-anal anastomosis. 
Colorectal Dis. 2008;11:67-72.

Oku H, Ogawa Y, Iwaoka E,Ishiguro K.Allergypreventive effects of chlorogenic acid and iridoid derivatives from flower buds of Lonicera japonica. Biol Pharm Bull. 2011;34(8):1330-1333.

Özyürek M, Bektaşoğlu B, Güçlü K, Apak R. Hydroxyl radical scavenging assay of phenolics and flavonoids with a modified cupric reducing antioxidant capacity (CUPRAC) method using catalase for hydrogen peroxide degradation. Anal Chim Acta. 2008;616(2):196-206.

Post-White J, Ladas EJ, Kelly KM. Advances in the use of milk thistle (Silybum marianum). Integr. Cancer Ther. 2007;6: 104-109.

Ramadan LA, Roushdy HM, Abu Senna GM, Amin NE, El-Deshw O. A Radioprotective effect of silymarin against radiation induced hepatotoxicity. Pharmacol Res. 2002; 45:447-54.

Reitman S, Frankel S. A colorimetric method for the determination of serum glutamic oxalacetic and glutamic pyruvic transaminases. Am J Clin Pathol. 1957; 28(1):56-63.

Rincón D, Lo Iacono O, Tejedor M, Hernando A, Ripoll C, Catalina MV, et al. Prognostic value of hepatic venous pressure gradient in patients with compensated chronic hepatitis C-related cirrhosis. Scand J Gastroenterol. 2013; 48: 487-495.

Saller R, Meier R, Brignoli R. The use of silymarin in the treatment of liver diseases. Drugs. 2001; 61(14):2035-2063.

Sanmugapriya E, Venkataraman S. Studies on hepatoprotective and antioxidant actions of Strychnos potatorum Linn. seeds on $\mathrm{CCl}_{4}$-induced acute hepatic injury in experimental rats. $J$ Ethnopharmacol. 2006;105:154-160.

Sehajpal J, Kaur T, Bhatti R, Singh AP. Role of progesterone in melatonin-mediated protection against acute kidney injury. J Sur Res. 2014; 191( 2): 441- 447.

Shankar NLG, Manavalan R, Venkappayya D, Raj CD. Hepatoprotective and antioxidant effects ofCommiphora berryi (Arn) Engl bark extract against CCl4-induced oxidative damage in rats. Food Chem Toxicol. 2008;46:3182-3185.

Shi H, Dong L, Bai Y, Zhao J, Zhang Y, Zhang L. Chlorogenic acid against carbon tetrachloride-induced liver fibrosis in rats. Eur J Pharmacol. 2009;623 (13): 119-124.

Singh B, Saxena AK, Chandan BK, Anand KK, Suri OP, Suri KA, et al. Hepatoprotective activity of verbenalin on experimental liver damage in rodents. Fitoter. 1998;69:135-140.

Tsochatzis EA, Bosch J, Burroughs AK. Liver cirrhosis. Lancet. 2014; 383: 1749-1761.

Turkdogan MK, Agaoglu Z, Yener Z, Sekeroglu R, Akkan HA, Avci ME. The role of antioxidant vitamins (C and E),selenium and Nigella sativa in the prevention of liver fibrosis and cirrhosis in rabbits: new hopes. Deutsche Tierarztliche Wochenschrift. 2001;108:71-73.

Virginia M, José LM, María VG, Paquita G, Juan PB, Javier G. Melatonin Is Able to Reduce the Apoptotic Liver Changes Induced by Aging Via Inhibition of the Intrinsic Pathway of Apoptosis. J Gerontol A Biol Sci Med Sci. 2007; 62 (7): 687-695.

Wang WZ, Fang XH, Stephenson LL, Zhang X, Khiabani KT, Zamboni WA. Melatonin attenuates I/Rinduced mitochondrial dysfunction in skeletal muscle. J Sur Res. 2011; 171(1): 108-113.

Wei Z, Rutao H, Tulei T. Silymarin's Protective Effects and Possible Mechanisms on Alcoholic Fatty Liver for Rats. Biomol Ther (Seoul). 2013; 21(4): 264-269.

Wray W, Boulikas T, Wray VP, Hancock R. Silver staining of proteins in polyacrylamide gels. Analytical Biochemistry. 1981;118:197-203.

Xiao J, Liong EC, Ching YP, Chang RC, So KF, Fung $\mathrm{ML}$, et al. Lycium barbarum polysaccharides protect mice liver from carbon tetrachloride-induced oxidative stress and ecroinflammation. $J$ Ethnopharmacol. 2012;139 (2), 462-470.

Xiao-Ling G, Bo L, Xue-Wei W, Fu-Gang F, Jing J, Rui $\mathrm{L}$, et al. Glycyrrhizic acid attenuates $\mathrm{CCl} 4$-induced hepatocyte apoptosis in rats via a p53-mediated pathway. World J Gastroenterol. 2013; 19(24): 37813791

$\mathrm{Xu} \mathrm{M}$, Ashraf M. Melatonin protection against lethal myocyte injury induced by doxorubicin as reflected by effects on mitochondrial membrane potential. $J$ Mol Cell Cardiol. 2002;34:75-79.

Yachi R, Osamu I, garashi O, Kiyose C. Protective effect of vitamin $\mathrm{E}$ against carbon tetrachloride induced fatty liver in rats. J Clin Biochem Nutr. 2010; 47: 148-154.

Yun-Chen T, Jung-Chun L, Chuan-Sung C, Tai-Hung H, Chih-Yang H, Wen-Te C, et al. Esculetin Ameliorates Carbon Tetrachloride-Mediated Hepatic Apoptosis in Rats. Int J Mol Sci. 2011;

Received: September 14, 2015; Accepted: December 16, 2015. 